\title{
A Wavelength Standard for the Near Infrared Based on the Reflectance Of Rare-Earth Oxides
}

\begin{tabular}{ll} 
Volume 91 & \multicolumn{1}{c}{ Number 5} \\
\hline $\begin{array}{l}\text { Victor R. Weidner, } \\
\text { Patricia Y. Barnes, and }\end{array}$ & $\begin{array}{l}\text { This work describes the techniques used } \\
\text { to prepare and analyze a reflectance } \\
\text { wavelength standard composed of three } \\
\text { rare-earth oxides. A mixture of dyspro- } \\
\text { sath L. Eckerle }\end{array}$ \\
$\begin{array}{l}\text { Gaithexide }\left(\mathrm{Dy}_{2} \mathrm{O}_{3}\right) \text {, erbium oxide } \\
\left(\mathrm{Er}_{2} \mathrm{O}_{3}\right) \text {, and holmium oxide }\left(\mathrm{Ho}_{2} \mathrm{O}_{3}\right) \\
\text { provides a pressed powder specimen ex- } \\
\text { hibiting a near infrared reflectance spec- } \\
\text { trum characterized by many discrete } \\
\text { absorption minima in the wavelength } \\
\text { range } 700 \text { to } 2000 \text { nm. The object of } \\
\text { this activity was to develop a wave- } \\
\text { length standard for improving the accu- } \\
\text { racy of reflectance measurements in the } \\
\text { near infrared. The reflectance minima } \\
\text { of the rare-earth oxide mixture was ana- } \\
\text { lyzed for the effects of varying spectral } \\
\text { resolution and temperature. The uncer- }\end{array}$
\end{tabular}

\begin{abstract}
tainties associated with the various parameters affecting the measurements and the determination of the location of the reflectance minima have been analyzed. The overall uncertainty in the location of these reflectance minima is believed not to exceed $\pm 1 \mathrm{~nm}$.
\end{abstract}

Key words: dysprosium oxide; erbium oxide; holmium oxide; near infrared reflectance; rare-earth oxides; spectral bandwidths; wavelength calibration; wavelength standard.

Accepted: February 28, 1985

\section{Introduction}

This work describes the techniques used to prepare and characterize a reflectance wavelength standard composed of three rare-earth oxides. A mixture of dysprosium oxide $\left(\mathrm{Dy}_{2} \mathrm{O}_{3}\right)$, erbium oxide $\left(\mathrm{Er}_{2} \mathrm{O}_{3}\right)$, and holmium oxide $\left(\mathrm{Ho}_{2} \mathrm{O}_{3}\right)$ provides a pressed powder specimen exhibiting a near infrared reflectance spectrum characterized by many discrete reflectance minima in the wavelength range 700 to $2000 \mathrm{~nm}$. This wavelength standard is primarily intended for checking the wavelength accuracy of spectrophotometric instrumentation designed for measuring diffuse reflectance in the near infrared.

About the Authors: Victor R. Weidner, Patricia Y. Barnes, and Kenneth L. Eckerle are with the Radiometric Physics Division in NBS' National Measurement Laboratory.

\section{Experimental}

\subsection{Instrumentation}

Measurements of spectral reflectance of the rareearth oxide mixture were made by means of a Varian-Cary Model 2390 recording spectrophotometer [1] $]^{1}$ The optical system of this double beam instrument consists of a filter predisperser and a double-pass monochromator with UV-VIS and near IR gratings. A deuterium lamp is used as a source for the ultraviolet spectral range. The visible and near infrared source is a tungsten-halogen lamp. The deuterium lamp also serves as a wavelength scale calibration source when the instrument is operated in a single beam mode, providing emission lines at 486.0 and $656.1 \mathrm{~nm}$ in the visible spec-

\footnotetext{
' Figures in brackets indicate literature references.
} 


\section{Journal of Research of the National Bureau of Standards}

trum and $2^{\text {nd }}, 3^{\text {rd }}$, and $4^{\text {th }}$ order lines of the $656.1 \mathrm{~nm}$ line with the near infrared grating.

The spectrophotometer is equipped with an integrating sphere diffuse reflectance reflectometer. This device is capable of measuring total hemispherical reflectance over the wavelength range 200 to $2500 \mathrm{~nm}$, using a photomultiplier detector for the ultraviolet and visible spectral range, and a lead sulfide detector for the near infrared. When operating with the lead sulfide detector, the reference mode (which determines the method used to control the reference signal level) operates at constant gain. The constant gain is maintained by varying the spectral bandwidth as a function of wavelength. The available range of spectral bandwidth settings is approximately 1 to $14 \mathrm{~nm}$ when using the diffuse reflectance attachment. The noise associated with the recording of a spectrum increases as the spectral bandwidth is narrowed and the spectral resolution must be sacrificed in order to maintain reasonable noise levels when recording spectra near the extreme short and long wavelength range of the lead sulfide detector. In order
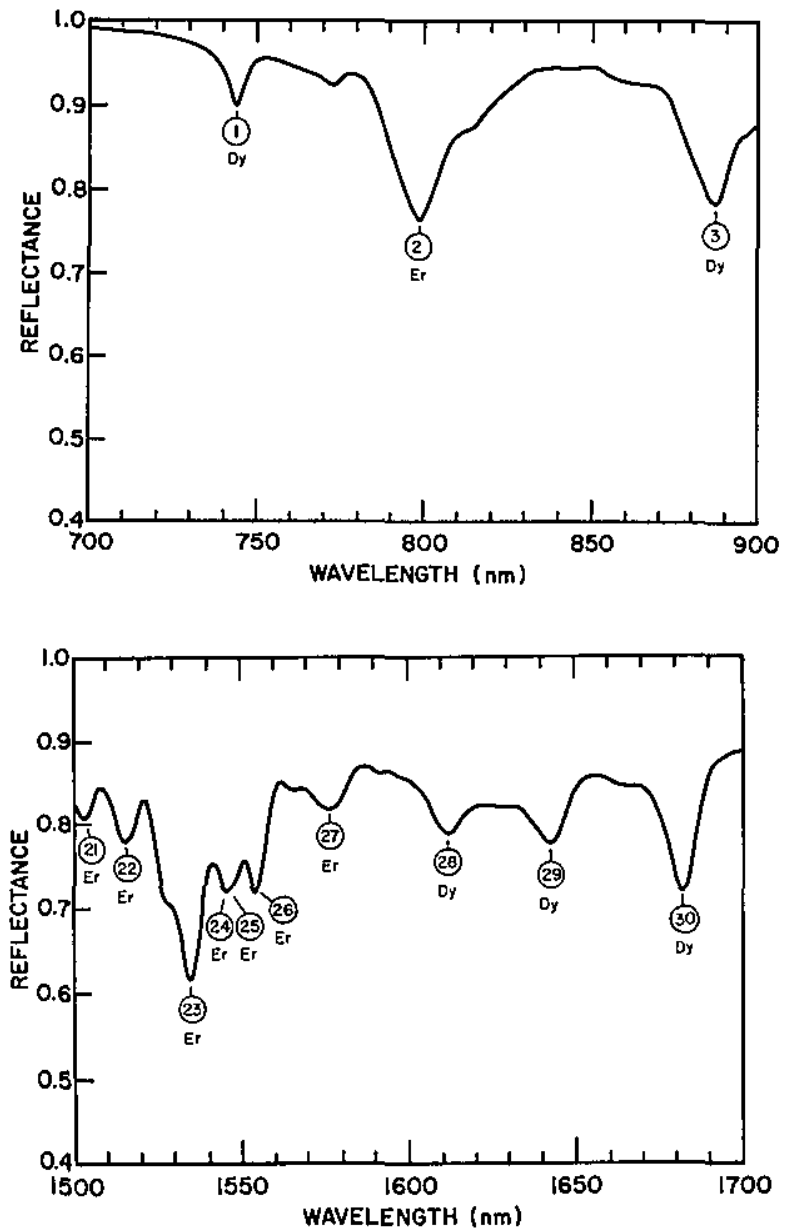

to record a spectrum over the full near infrared spectral range at approximately constant resolution, the gain must be reset every 25 to $50 \mathrm{~nm}$. When constant resolution is not important, a complete scan of the near infrared range can be made at a fixed gain setting. For the measurements described in this work, the control of spectral resolution was of primary importance and gain settings were varied to provide a number of fixed spectral bandwidths for analysis of the effects of resolution on the location of the wavelengths of minimum reflectance of the rare-earth oxide mixture.

\subsection{Materials}

2.2.1 Rare-Earth Oxides. The rare-earth oxides of dysprosium, erbium, and holmium were selected for preparation of the reflectance wavelength studies after extensive measurements of the near infrared reflectance spectra of numerous rare-earth oxides. None of the single component rare-earth specimens analyzed exhibited enough absorption bands to serve as a wavelength standard for the full
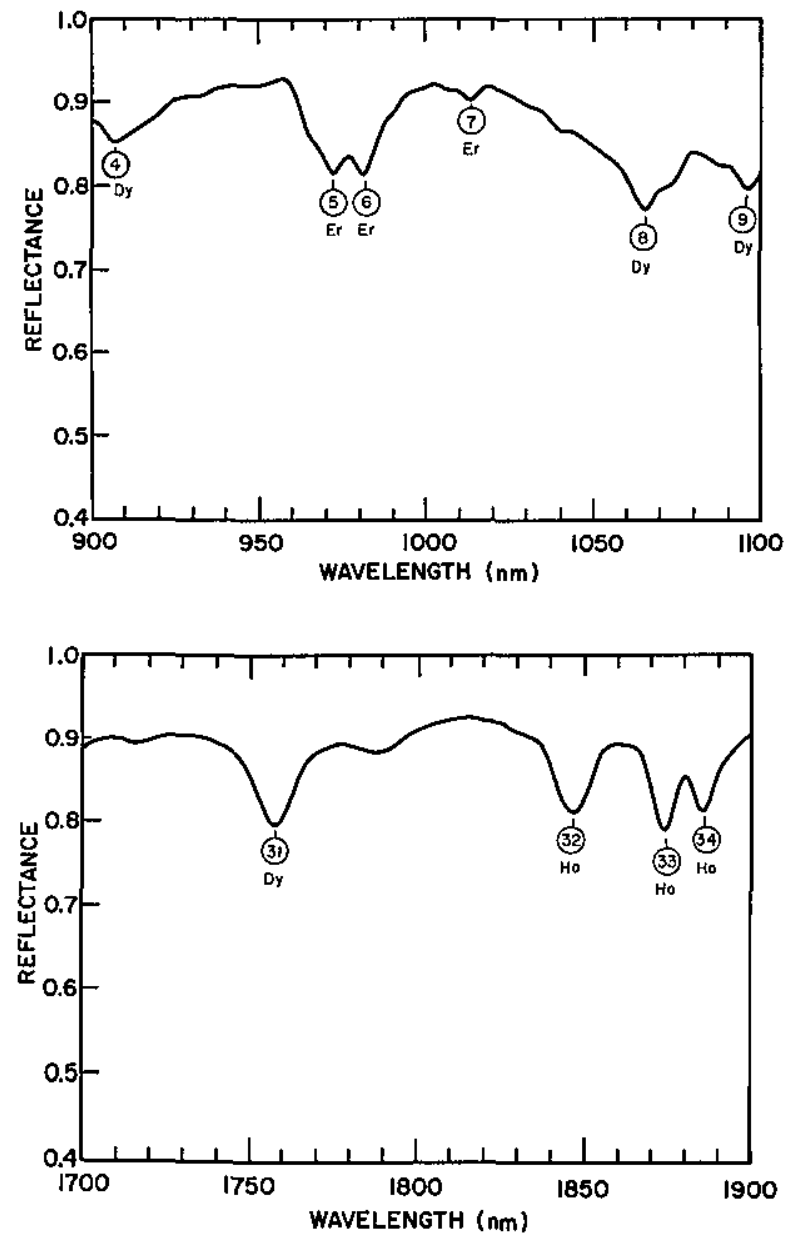


\section{Journal of Research of the National Bureau of Standards}

700 to $2500 \mathrm{~nm}$ spectral range and none showed any promise at wavelengths much beyond 2000 $\mathrm{nm}$. The oxides of dysprosium, erbium, and holmium were selected because their infrared absorption bands occurred at various wavelengths throughout the 700 to $2000 \mathrm{~nm}$ spectral range with a minimum of overlapping of the bands attributed to each oxide. The disadvantage of mixing the three component rare-earth oxides was the loss of some intensity of depth of the individual absorption bands. The reflectance spectra of the three component rare-earth oxide mixture is illustrated in figures 1-1 through 1-7 for a nominal spectral bandwidth of $4 \mathrm{~nm}$. The absorption features selected for analysis are numbered 1-37 and the rareearth oxide attributed to each of these absorption features is identified by the elemental symbols Dy, $\mathrm{Er}$, and Ho appearing with each band number.

The three rare-earth oxides were mixed in equal parts by weight. The purity of each rare-earth oxide was indicated by the manufacturer [2] to be 99.99 percent. The specimens are identified by lot numbers; (Dy: lot no. Dy-0-4-018), (Er: lot no. Er-
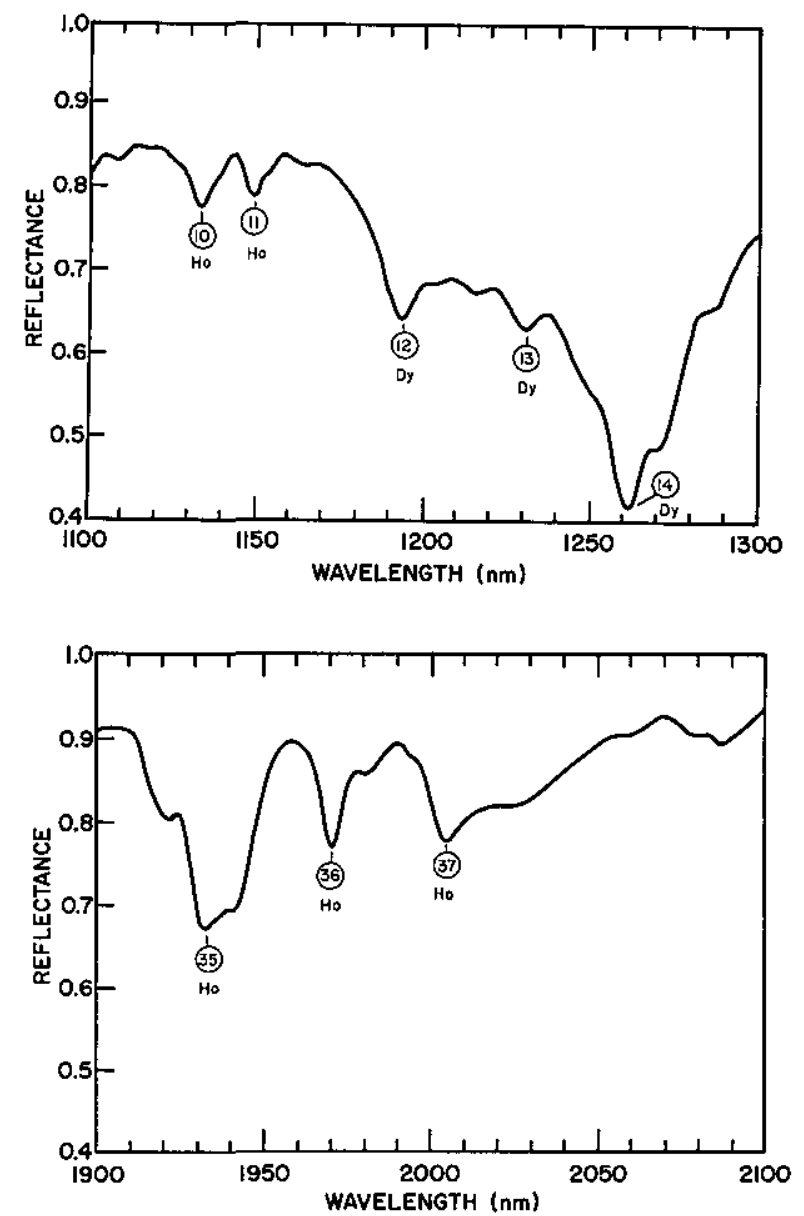

0-4-028), and (Ho: lot no. Ho-0-4-007). Each rareearth oxide was weighed in portions of $2 \mathrm{~g} \pm 0.01 \mathrm{~g}$. These were combined to form a total weight of $6 \mathrm{~g}$. After throughly mixing the three components, the mixture was pressed into an aluminum cavity having a depth of $0.5 \mathrm{~cm}$ and diameter of $2.85 \mathrm{~cm}$. This produced a specimen with a powder density of approximately $2 \mathrm{~g} / \mathrm{cm}^{3}$. The powder specimen was provided with a sapphire window of $1.5 \mathrm{~mm}$ thickness. This window retained the powder and protected it against damage and contamination. Sapphire was selected as a window material because it is essentially free of absorption features in the near infrared.

\subsection{Measurement Techniques}

2.3.1 Calibration of the Spectrophotometer Wavelength Scale. The spectrophotometer wavelength scale error was evaluated by measuring the emission lines of the following elements: neon at $703.24 \mathrm{~nm}$, xenon at 881.94 and $979.97 \mathrm{~nm}$, mercury at 1013.97 and $1529.58 \mathrm{~nm}$, and krypton at 1816.73

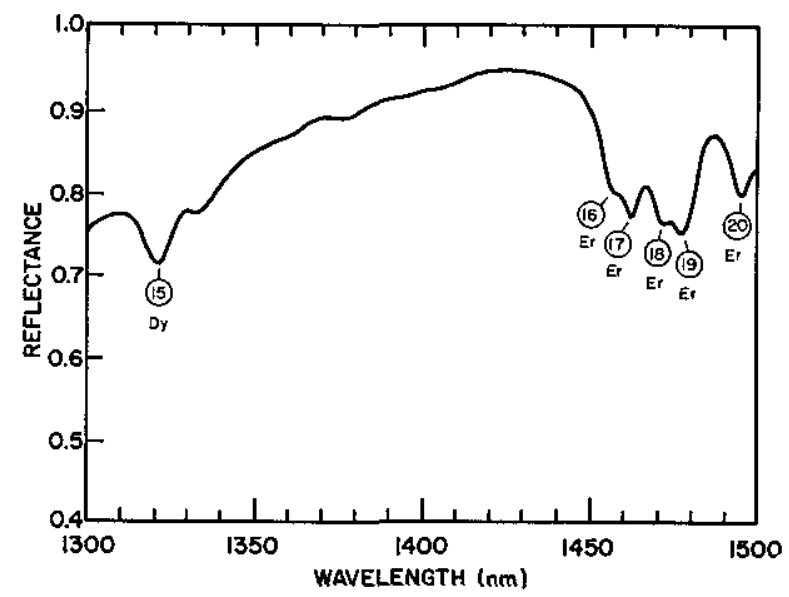

Figures 1-1 through 1-7-Beginning upper left at a wavelength $700 \mathrm{~nm}$ the near infrared spectral reflectance of a rare-earth oxide mixture composed of $\mathrm{Dy}_{2} \mathrm{O}_{3}, \mathrm{Er}_{2} \mathrm{O}_{3}$, and $\mathrm{Ho}_{2} \mathrm{O}_{3}$ in equal portions by weight compressed to a density of $1 \mathrm{~g} / \mathrm{cm}^{3}$. 
nm. [3] In addition to these, the absorption band of 1-2-4 trichlorobenzene at $2152.60 \mathrm{~nm}$ [4] was also measured.

The wavelength scale of the spectrophotometer was calibrated at the beginning of the study and again after completion of the spectral analysis of the rare-earth oxide spectra. The day-to-day stability of the instrument wavelength scale was monitored by recording the $2^{\text {nd }}$ order emission of the $656.1 \mathrm{~nm}$ deuterium line at $1312.2 \mathrm{~nm}$ after a nominal warm-up time of 1 hour. The record of this day-to-day stability check is illustrated in figure 2 for the time period of November 13 to December 24. The data in figure 2 show that the

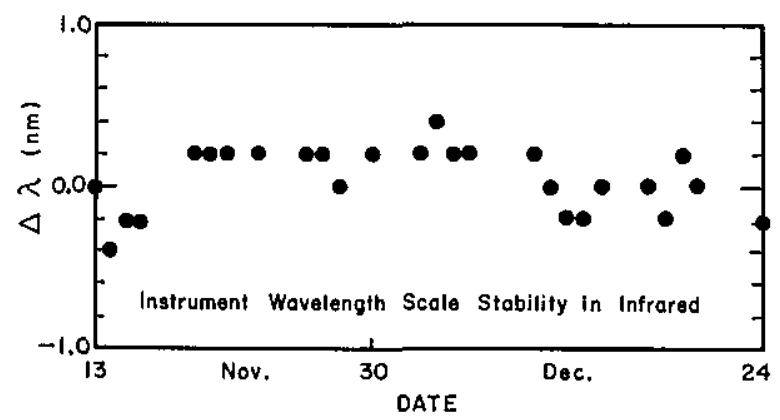

Figure 2-The day-to-day record of the stability of the spectrophotometer wavelength scale in the near-infrared. wavelength scale was stable to $\pm 0.2 \mathrm{~nm}$ during this time interval.

The wavelength error was evaluated by scanning the emission lines at a rate of $0.01 \mathrm{~nm} / \mathrm{sec}$. and recording the resulting spectrum on a scale of 0.2 $\mathrm{nm} / \mathrm{cm}$. The recorded emission peaks were bisected, using a proportional divider, to determine the wavelengths at the center of the recorded triangular lines. Using this technique, the wavelength scale was read to the nearest $0.01 \mathrm{~nm}$.

The wavelength errors were evaluated for spectral bandwidths of $2,3,4,5$, and $10 \mathrm{~nm}$. The differences between the published or "true" wavelengths of the emission lines as determined from the measurements on the spectrophotometer, are plotted in figures 3-1 and 3-2 for analysis of the instrument wavelength error. The data points were found to be closely grouped for the measurements at spectral bandwidths of $2,3,4$, and $5 \mathrm{~nm}$. The data points for the $10 \mathrm{~nm}$ spectral bandwidth measurements were somewhat separated from the others. For this reason the analysis of the 2, 3, 4, and $5 \mathrm{~nm}$ bandwidth data are illustrated in figure 3-1 and the $10 \mathrm{~nm}$ bandwidth data in figure 3-2. Since the dayto-day wavelength scale stability check indicates a possible point spread of $0.4 \mathrm{~nm}$, this grouping of the bandwidth data into one group for the $2,3,4$, and $5 \mathrm{~nm}$ measurements seemed reasonable.
Figure 3-1 (upper) and Figure 3-2The wavelength scale calibration results for the selected spectral bandwidths showing the data point spread (vertical bars), data point averages (open circles on the vertical bars), the linear least-squares fit to the data point averages (sloping solid straight line).
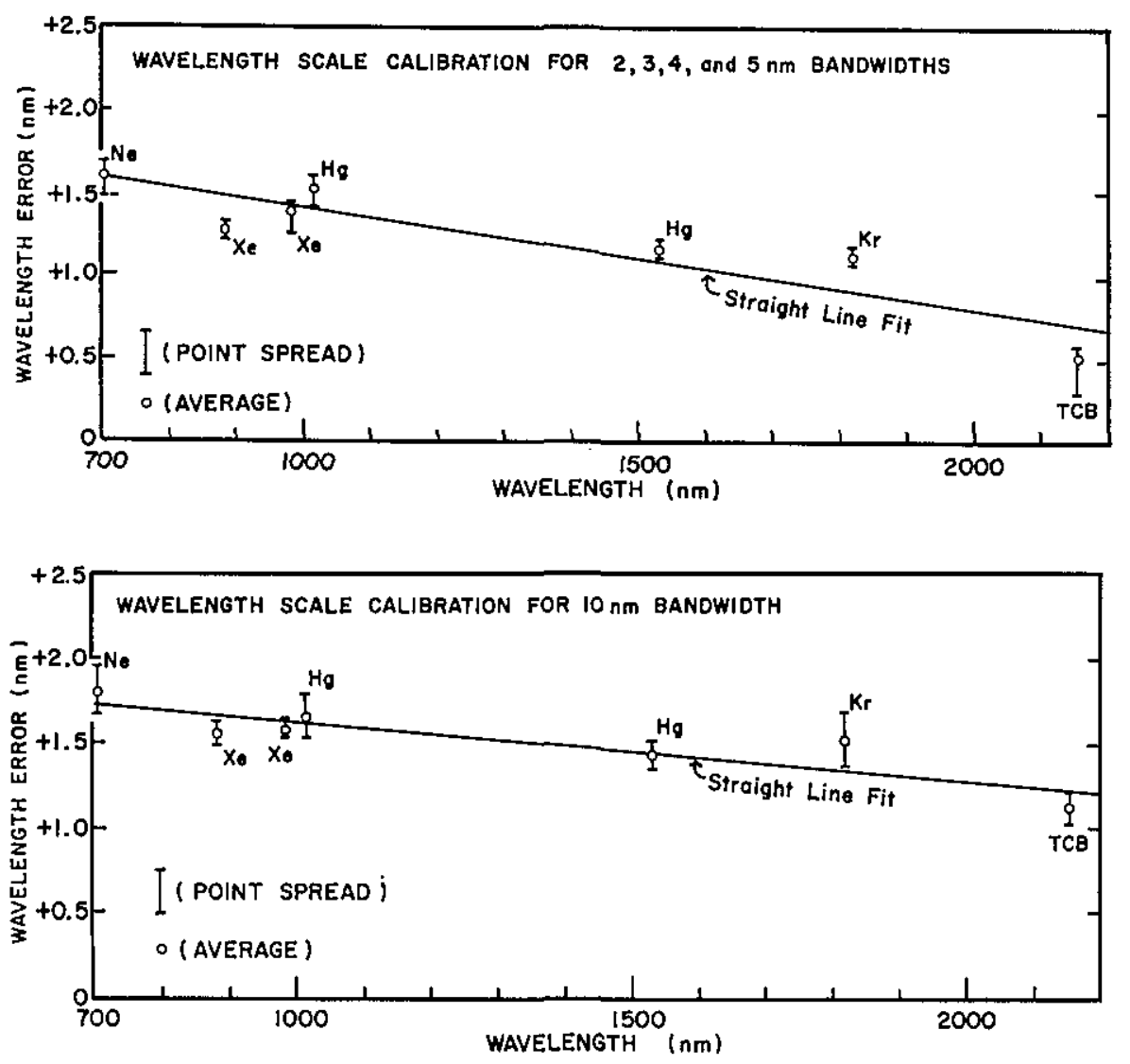
The spread of data points in figures 3-1 and 3-2 is indicated by the vertical bars. The average of the data points within the vertical bar is indicated by the open circle on the bar. A linear least-squares fit of the the average data points, (represented by the open circles), is shown as a straight line across the graph. This line was taken as a indication of the wavelength scale error of the spectrophotometer for these spectral bandwidths over the near infrared spectral range 700 to $2150 \mathrm{~nm}$. This linear least-squares fit represents a nominal wavelength correction. The data spread bars shown in figures 3-1 and 3-2 are sometimes completely above or below the least-squares fit. Repeated measurements probably would not improve the fit because of hidden factors that influence where a particular emission line will appear.

A mathematical estimation of the uncertainty in the calibration of the instrument wavelength scale can be derived from the sum of the following observed uncertainties:

The wavelength scale uncertainty $(a)$ is:

$$
a=2 d+r+v
$$

where:

$2 d=$ twice the standard deviation of the linear least-squares fit for the emission line wavelengths,

$r=1 / 2$ the range of the data point spread

for the worst case for location of an emis-

sion line,

$v=$ the day-to-day stability of the

wavelength scale.

For the 2, 3, 4, and $5 \mathrm{~nm}$ spectral bandwidths:

$$
a= \pm 0.57 \mathrm{~nm}
$$

For a $10 \mathrm{~nm}$ spectral bandwidth:

$$
a= \pm 0.66 \mathrm{~nm} \text {. }
$$

Other uncertainties associated with the overall determination of the wavelengths of minimum reflectance of the rare-earth oxide mixture will add to these uncertainties. These uncertainties will be discussed in section 2.3.4.

2.3.2 Spectral Bandwidths. The spectral bandwidth settings used in the analysis of the rare-earth oxide mixture were selected to provide data on the effect of changing resolution on the location of the reflectance minima that are characteristic of this material in the near infrared. The spectral bandwidths in the near infrared are controlled by adjusting the reference signal gain. This adjustment involves the monochromator slit width mechanism which in effect controls the spectral bandwidth or resolution. The bandwidth is displayed on the instrument control panel. In order to check the validity of the spectral bandwidth readout on the display panel, a series of measurements were made of the half-band widths of the mercury emission line at $1014 \mathrm{~nm}$ for nominal bandwidth settings of $2,3,4,5$, and $10 \mathrm{~nm}$. In the single beam mode of operation the gain can be adjusted without changing the selected bandwidth. The half-band width is determined by scanning the emission line with the gain adjusted until the peak of the emission is approximately 100 percent. The measured width of the recorded emission spectra at half the peak height is an indication of the spectral bandwidth. A comparison of the nominal spectral bandwidth, as indicated on the instrument display panel, and the measured half-band width of the mercury emission spectra is given in table 1 . The comparison shows that the actual bandwidths are less than the nominal bandwidths for the $2,3,4$, and $5 \mathrm{~nm}$ settings and the same for the $10 \mathrm{~nm}$ setting.

2.3.3 Determination of the Wavelength of Minimum Reflectance. The spectral reflectance of the rare-earth oxide mixture is shown in figures 1-1 through 1-7 for a nominal spectral bandwidth of 4 $\mathrm{nm}$. The number of observed absorption bands varies as a function of the spectral bandwidth setting selected for recording the spectrum. There are 37 reflectance minima identified in the figures. Most can be observed at bandwidths less than 4 $\mathrm{nm}$. Only a few can be observed at $10 \mathrm{~nm}$ spectral bandwidth.

The reflectance spectra of the mixture of rareearth oxides was recorded on a chart with a wavelength display of $0.5 \mathrm{~nm} / \mathrm{cm}$ and a wavelength scan range of $0.05 \mathrm{~nm} / \mathrm{sec}$. This speed is a relatively slow scan rate for these absorption bands so that the effect of recorder inertia error is essentially eliminated as a source of wavelength scale error.

The reflectance was measured with a sapphire window between the rare-earth oxide mixture and the sample port of the integrating sphere of the reflectometer. The 100 percent (baseline) calibration was set with a pressed powder Halon (polytetrafluoroethylene) specimen, also covered by a sapphire window. The near infrared spectral reflectance of a sapphire window covered Halon

Table 1. Comparison of the spectral bandwidths as indicated by the instrument readout (A) with the spectral bandwidths as derived from the half-height bandwidth measurements of the $1014 \mathrm{~nm} \mathrm{Hg}$ emission line (B).

\begin{tabular}{cc}
\hline \multicolumn{2}{c}{ Spectral Bandwidths } \\
\hline$(A)$ & $(B)$ \\
$2 \mathrm{~nm}$ & $1.4 \mathrm{~nm}$ \\
3 & 2.6 \\
4 & 3.6 \\
5 & 4.6 \\
10 & 10.0 \\
\hline
\end{tabular}


specimen versus an uncovered Halon Specimen (100 percent) is shown in figure 4 . The spectral transmittance of the sapphire window is also shown in figure 4.

The determination of the wavelengths of minimum reflectance of the rare-earth mixture was accomplished through an analysis of the recorded spectral curves. The location of the wavelengths of minimum reflectance for a given absorption band was graphically determined by bisecting the absorption band. The technique is illustrated in figure 5. The horizontal grid lines of the chart paper that intersect the two slopes of the absorption band are bisected by means of a proportional divider. The points of bisection locate a line between the two slopes that intersects the minimum reflectance point, (usually at the lowest point of the curve). The wavelength at this point of intersection was taken as the measured wavelength of minimum reflectance for the absorption feature. The true wavelength of the minimum was determined by applying a wavelength correction to this measured value. This correction was discussed in section 2.3.1. Various uncertainties are associated with these assigned true wavelengths. These will be discussed in section 2.3.4.

2.3.4 Accuracy of the Wavelengths of Minimum Reflectance. The overall uncertainty in the location of the wavelengths of minimum reflectance is believed to be no greater than $\pm 1 \mathrm{~nm}$. This conclusion is based on the reproducibility of the following calibration parameters:

a) The uncertainty of the calibration of the spectrophotometer wavelength scale using

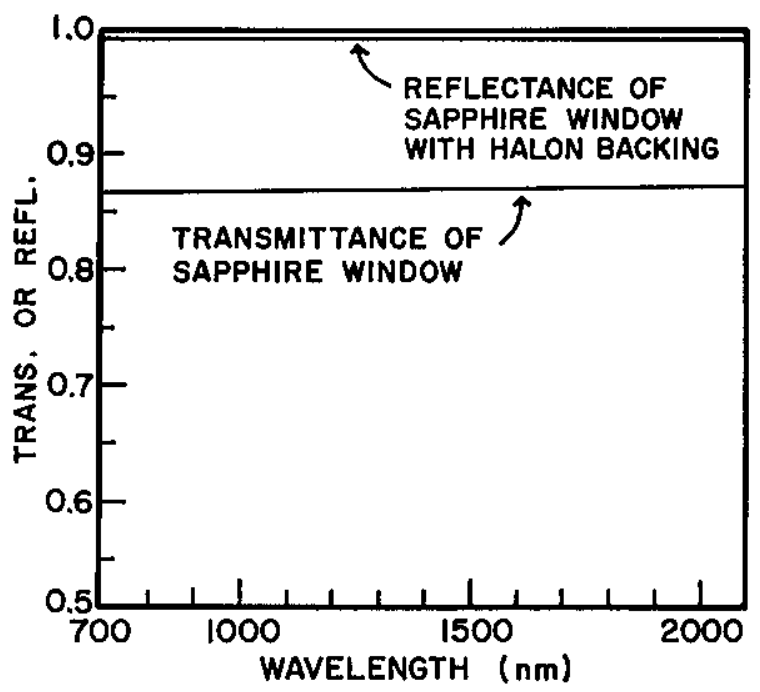

Figure 4-The spectral transmittance of the sapphire window used to cover the rare-earth oxide pressed powder specimen, and the spectral reflectance of a sapphire window covering the Halon diffuse reflectance standard.

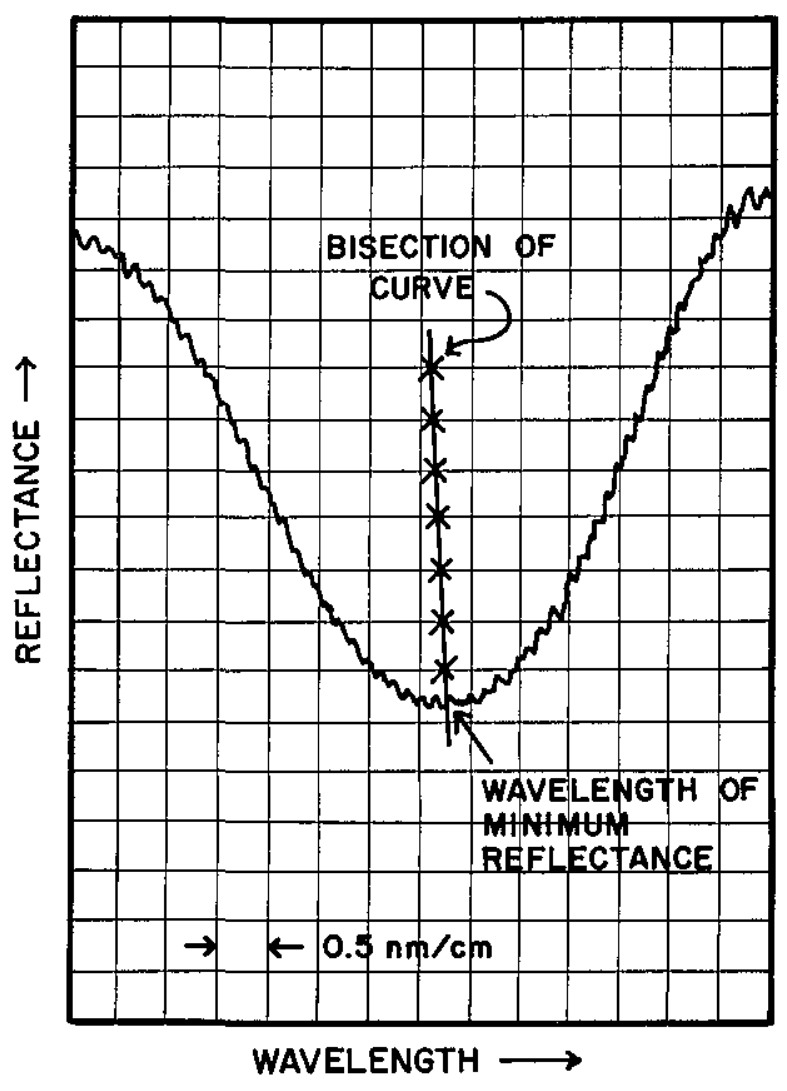

Figure 5-The wavelengths of minimum reflectance are determined by bisecting the recorded absorption feature as illustrated in this example.

the emission lines of $\mathrm{Ne}, \mathrm{Xe}, \mathrm{Hg}$, and $\mathrm{Kr}$, and the absorption band of 1-2-4 trichlorobenzene, and the day-to-day instabilities of the instrument; $( \pm 0.57 \mathrm{~nm}$ and $\pm 0.66 \mathrm{~nm}$ depending on the spectral bandwidth).

b) The imprecision of the graphical technique for deriving the measured wavelengths of minimum reflectance; $( \pm 0.41 \mathrm{~nm})$, (twice the largest standard deviation), (see table 2).

c) The maximum observed temperature effect; $( \pm 0.15 \mathrm{~nm})$.

A mathematical estimation of the overall uncertainty $(T)$ in the location of the wavelengths of minimum reflectance can be derived from the square root of the sum of the independent errors squared:

$$
\mathrm{T}=\sqrt{a^{2}+b^{2}+c^{2}}
$$

where:

$$
\begin{aligned}
& a=\text { uncertainty in the instrument wavelength } \\
& \text { scale, }
\end{aligned}
$$




\section{Journal of Research of the National Bureau of Standards}

Table 2. Ten measurements of the reflectance minima for each of three absorption bands at a spectral bandwidth of $4 \mathrm{~nm}$, showing the spread of values obtained by the graphical location of the minima. The average, standard deviation, and standard error for the ten values are also given. These measurements are for $25^{\circ} \mathrm{C}$

\begin{tabular}{|c|c|c|c|c|}
\hline \multicolumn{2}{|c|}{$\begin{array}{l}\text { Measurement } \\
\text { No. }\end{array}$} & $\begin{array}{l}\text { Band No. } 14 \\
\left(\mathrm{Dy}_{2} \mathrm{O}_{3}\right)\end{array}$ & $\begin{array}{l}\text { Band No. } 23 \\
\left(\mathrm{Er}_{2} \mathrm{O}_{3}\right)\end{array}$ & $\begin{array}{l}\text { Band No. } 32 \\
\left(\mathrm{Ho}_{2} \mathrm{O}_{3}\right)\end{array}$ \\
\hline & 1 & 1261.00 & 1535.68 & 1847.09 \\
\hline & 2 & 1260.93 & 1535.65 & 1847.00 \\
\hline & 3 & 1261.15 & 1535.70 & 1846.77 \\
\hline & 4 & 1261.00 & 1535.70 & 1847.00 \\
\hline & 5 & 1261.03 & 1535.60 & 1846.73 \\
\hline & 6 & 1261.20 & 1535.65 & 1846.78 \\
\hline & 7 & 1261.08 & 1535.63 & 1846.50 \\
\hline & 8 & 1260.93 & 1535.60 & 1846.70 \\
\hline & 9 & 1260.93 & 1535.69 & 1846.73 \\
\hline & 10 & 1261.00 & 1535.70 & 1846.43 \\
\hline \multicolumn{2}{|c|}{ Average } & 1261.03 & 1535.66 & 1846.77 \\
\hline \multicolumn{5}{|c|}{ Standard } \\
\hline Deviat & tion & 0.09 & 0.04 & 0.21 \\
\hline \multicolumn{5}{|c|}{ Standard } \\
\hline Error & & 0.03 & 0.01 & 0.07 \\
\hline Note: & \multicolumn{4}{|c|}{$\begin{array}{l}\text { The data in this table have not been corrected for the } \\
\text { wavelength scale error of the spectrophotometer. }\end{array}$} \\
\hline
\end{tabular}

For spectral bandwidths of 2, 3, 4, and $5 \mathrm{~nm}$ :

$T= \pm 0.72 \mathrm{~nm}$

For a spectral bandwidth of $10 \mathrm{~nm}$ :

$T= \pm 0.79 \mathrm{~nm}$.

These uncertainties are for a 95 percent confidence level. Some other possible uncertainties are discussed in the conclusion.

\section{Measurements}

\subsection{Influence of the Sapphire Window and the Base- line Calibration}

In measuring diffuse spectral reflectance, some reference must be used to establish a 100 percent level (baseline). In this double beam spectrophotometer, the reference beam enters the integrating sphere and is incident on a Halon target. The sample beam enters through another port and is incident on the sample. In order to establish a 100 percent level calibration curve, a sample of pressed Halon is placed at the sample port. The 100 percent level is established by the ratio of the sample (Halon) reflectance to the reference beam signal (also Halon). The instrument records this baseline in a computer memory. When the Halon sample is replaced by a test specimen, the reflectance of the specimen is recorded relative to this stored baseline or 100 percent level. This method is called the substitution method. The reflectance of the test specimen is a relative measurement. Halon is used to establish the 100 percent level because its absolute reflectance is very high and it has no significant absorption features that would introduce a distortion in the recorded spectra. The absolute reflectance of the test specimen can be obtained by adjusting the relative measurement to the absolute reflectance of the Halon [5].

In this study a sapphire window is placed over the rare-earth oxide test specimen. This window is $1.5 \mathrm{~mm}$ thick. A similar window is placed over the Halon sample during the recording of the 100 percent level. By using a sapphire window on both the Halon and the rare-earth oxide specimens, the effects of the window reflectance and absorbance are cancelled out in the baseline calibration.

The sapphire window has no absorption bands in the near infrared that would influence the determination of the wavelength of minima reflectance of the rare-earth oxide mixture. The absolute reflectance data for Halon [5] also show that it can be used as a baseline standard for purposes of this investigation.

\subsection{Influence of Spectral Bandwidth}

The effects of spectral bandwidth on the location of the rare-earth oxide reflectance minima are shown in table 3 . The absorption bands are numbered from 1 at approximately $742 \mathrm{~nm}$ to 37 at approximately $2005 \mathrm{~nm}$. Measurements were made at nominal spectral bandwidths based on the instrument display readout of this parameter. However, the data listed in table 1 indicate that the spectral bandwidths were less than the nominal values for all but the $10 \mathrm{~nm}$ setting.

The blank spaces in table 3 are blank for the following reasons: (1) The noise level was too large to make reliable measurements. This was the case for bands $1,2,36$, and 37 at the $2 \mathrm{~nm}$ spectral bandwidth setting. (2) Two adjacent bands merged together because the selected spectral bandwidths did not resolve the two bands. This was the case for bands 24 and 25 at $3 \mathrm{~nm}$ spectral bandwidth. (3) The band became too shallow due to the large spectral bandwidth. This case occurs for many of the bands at 5 and $10 \mathrm{~nm}$ spectral bandwidths.

Table 3 does not give a clear picture of the exact effects of changing spectral bandwidth on the location of the the wavelengths of minimum reflec- 


\section{Journal of Research of the National Bureau of Standards}

Table 3. The adopted wavelengths of minimum reflectance for the rare-earth oxide mixture at $25^{\circ} \mathrm{C}$ and for spectral bandwidths (SBW) of 2, 3, 4, 5, and $10 \mathrm{~nm}$.

\begin{tabular}{|c|c|c|c|c|c|c|}
\hline $\begin{array}{l}\text { Rare-earth } \\
\text { oxide }\end{array}$ & $\begin{array}{l}\text { Band } \\
\text { No. }\end{array}$ & $\begin{array}{l}\text { SBW } \\
2 \mathrm{~nm}\end{array}$ & $\begin{array}{l}\text { SBW } \\
3 \mathrm{~nm}\end{array}$ & $\begin{array}{c}\text { SBW } \\
4 \mathrm{~nm}\end{array}$ & $\begin{array}{c}\text { SBW } \\
5 \mathrm{~nm}\end{array}$ & $\begin{array}{c}\text { SBW } \\
10 \mathrm{~nm}\end{array}$ \\
\hline $\mathrm{Dy}_{2} \mathrm{O}_{3}$ & 1 & .... & 743.0 & 743.4 & 743.4 & -..-. \\
\hline " & $2^{*}$ & - & 799.0 & 799.0 & 798.6 & 798.0 \\
\hline " & $3^{*}$ & 887.2 & 886.9 & 886.7 & 886.7 & 886.5 \\
\hline "* & 4 & 906.3 & 906.8 & 907.5 & 907.3 & ---- \\
\hline $\mathrm{Er}_{2} \mathrm{O}_{3}$ & 5 & 970.6 & 971.3 & 971.6 & 971.6 & -.... \\
\hline$"$ & 6 & 979.6 & 980.8 & 980.8 & 980.8 & ..... \\
\hline " & 7 & 1012.9 & 1013.2 & 1012.9 & 1012.8 & $-\cdots$ \\
\hline $\mathrm{Dy}_{2} \mathrm{O}_{3}$ & 8 & 1064.7 & 1065.0 & 1065.0 & 1064.9 & -...- \\
\hline " & 9 & 1095.6 & 1096.0 & 1096.2 & 1096.4 & 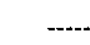 \\
\hline $\mathrm{Ho}_{2} \mathrm{O}_{3}$ & $10^{*}$ & 1132.2 & 1132.3 & 1132.4 & 1132.9 & 1132.9 \\
\hline " & $11^{*}$ & 1148.1 & 1148.4 & 1148.5 & 1148.7 & 1148.6 \\
\hline $\mathrm{Dy}_{2} \mathrm{O}_{3}$ & 12 & 1192.9 & 1192.7 & 1192.9 & 1192.9 & - \\
\hline " & 13 & 1230.2 & 1230.2 & 1230.2 & 1230.3 & -... \\
\hline “ & $14^{*}$ & 1261.0 & 1260.9 & 1260.8 & 1260.8 & 1261.8 \\
\hline “ & 15 & 1320.7 & 1320.7 & 1320.8 & 1320.7 & 1320.2 \\
\hline $\mathrm{Er}_{2} \mathrm{O}_{3}$ & 16 & 1456.2 & 1456.4 & 1456.7 & -...- & --- \\
\hline 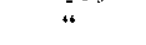 & 17 & 1461.7 & 1461.9 & 1462.2 & ..... & --- \\
\hline " & 18 & 1471.2 & 1471.6 & 1471.6 & ..... & ..... \\
\hline “ & 19 & 1477.4 & 1477.6 & 1477.5 & -.-- & $\ldots$ \\
\hline “ & 20 & 1494.8 & 1494.9 & 1495.0 & 1495.0 & -... \\
\hline “ & 21 & 1503.4 & 1503.5 & 1503.5 & .... & -..-. \\
\hline$"$ & 22 & 1516.0 & 1516.0 & 1515.9 & 1515.7 & $\cdots$ \\
\hline$"$ & $23^{*}$ & 1535.5 & 1535.6 & 1535.6 & 1535.4 & 1534.6 \\
\hline * & 24 & 1544.7 & --.- & ---- & -..- & ---.- \\
\hline “ & 25 & 1548.1 & -.-- & ..... & ---- & -..- \\
\hline “. & 26 & 1555.1 & 1555.0 & 1554.8 & -..- & --- \\
\hline$"$ & 27 & 1577.1 & 1577.2 & 1577.2 & ‥-- & ....- \\
\hline $\mathrm{Dy}_{2} \mathrm{O}_{3}$ & 28 & 1611.8 & 1611.7 & 1611.7 & 1611.9 & -..- \\
\hline " & 29 & 1642.7 & 1642.7 & 1642.5 & 1642.5 & - \\
\hline “" & $30^{*}$ & 1682.6 & 1682.3 & 1682.2 & 1682.2 & 1681.4 \\
\hline “ & $31^{*}$ & 1757.6 & 1757.8 & 1757.9 & 1757.8 & 1757.6 \\
\hline $\mathrm{Ho}_{2} \mathrm{O}_{3}$ & $32^{*}$ & 1847.5 & 1847.3 & 1846.9 & 1847.0 & 1847.3 \\
\hline " & 33 & 1874.3 & 1874.0 & 1873.8 & 1874.0 & ---- \\
\hline “ & 34 & 1885.0 & 1885.3 & 1885.7 & 1885.5 & -.... \\
\hline$"$ & $35^{*}$ & 1930.9 & 1931.6 & 1932.2 & 1932.5 & 1935.5 \\
\hline$"$ & $36^{*}$ & ..... & 1970.6 & 1970.7 & 1970.8 & 1970.8 \\
\hline$"$ & 37 & -.-- & 2004.5 & 2005.9 & 2005.8 & 2006.3 \\
\hline
\end{tabular}

The uncertainty in the wavelengths of minimum reflectance are believed to be no greater than $\pm 1 \mathrm{~nm}$.

* (preferential bands)

tance for the rare-earth oxide absorption bands because some of the uncertainties discussed in section 2.3.4 are large enough to mask the bandwidth effects. However, the apparent shift in the wavelengths of the minima are sometimes larger than the overall uncertainty. Therefore, all the results are listed in the table.

For purposes of checking the wavelength scale of a reflectance spectrophotometer there are many reflectance minima listed in table 3 . A few of the minima might be considered as being preferable because the absorption bands are observed at bandwidths as large as $10 \mathrm{~nm}$. These bands are marked with an asterisk after the band number in the table.

\subsection{Influence of Temperature}

All the data listed in table 3 was obtained at a temperature of $25^{\circ} \mathrm{C} \pm 0.5^{\circ} \mathrm{C}$. The effects of temperature on the location of the wavelengths of minimum reflectance of the rare-earth oxide mixture were studied by analyzing one absorption band for each of the three rare-earth components. The results are shown in table 4 for bands 14,23 , and 32 , at $20^{\circ} \mathrm{C}, 25^{\circ} \mathrm{C}$, and $30^{\circ} \mathrm{C}$. These measurements were made with a spectral bandwidth of $4 \mathrm{~nm}$. Because these measurements did not prove or disprove the effects of temperature, and effect was as- 


\section{Journal of Research of the National Bureau of Standards}

Table 4. The observed effects of temperature on the wave lengths of minimum reflectance for $20^{\circ} \mathrm{C}, 25^{\circ} \mathrm{C}$, and $30^{\circ} \mathrm{C}$. The temperature effects are not revealed by the observed differences because of larger uncertainties discussed in section 2.3.4.

\begin{tabular}{|c|c|c|c|}
\hline \multicolumn{4}{|c|}{ (spectral bandwidth $=4 \mathrm{~nm}$ ) } \\
\hline Temperature & $\begin{array}{l}\text { Band No. } 14 \\
\left(\mathrm{Dy}_{2} \mathrm{O}_{3}\right)\end{array}$ & $\begin{array}{l}\text { Band No. } 23 \\
\left(\mathrm{Er}_{2} \mathrm{O}_{3}\right)\end{array}$ & $\begin{array}{c}\text { Band No. } 32 \\
\left(\mathrm{Ho}_{2} \mathrm{O}_{3}\right)\end{array}$ \\
\hline $20^{\circ} \mathrm{C}$ & $1260.8 \mathrm{~nm}$ & $1535.7 \mathrm{~nm}$ & $1847.0 \mathrm{~nm}$ \\
\hline $25^{\circ} \mathrm{C}$ & 1260.8 & 1535.6 & 1846.9 \\
\hline $30^{\circ} \mathrm{C}$ & 1261.0 & 1535.5 & 1846.7 \\
\hline
\end{tabular}

sumed based on the largest differences observed for the data in table 4 for purposes of estimating the overall uncertainty (see sec. 2.3.4).

\subsection{Influence of Instrument Sensitivity Function}

The instrument function is the relative sensitivity of the instrument as a function of wavelength as observed in the single beam mode of operation with no sample in the beam. The instrument sensitivity is influenced by a number of parameters such as the energy output of the source as a function of wavelength, grating efficiency, reflection of mirrors, transmission of windows, and spectral response of the detector. The near infrared instrument sensitivity of the Varian-Cary 2390 spectrophotometer, increases from $700 \mathrm{~nm}$ to approximately $1150 \mathrm{~nm}$, then decreases with increasing wavelength. There are some local variations in this sensitivity curve due to absorption features associated with optics and atmospheric conditions. The effect of the instrument sensitivity function on the wavelengths at which absorption features appear for a specimen being scanned is to shift the scale to longer wavelength when the instrument sensitivity is increasing from shorter wavelength to longer wavelength (positive slope) and to shift the scale to shorter wavelength when the instrument sensitivity is decreasing from shorter wavelength to longer wavelength (negative slope). The amount of wavelength shift increases as the slope becomes steeper with changing wavelength.

The shift in wavelength due to the influence of the instrument sensitivity can be determined to a close approximation, using the following equation:

$$
d \lambda=\frac{a w^{2}}{6}
$$

where:

$$
\begin{aligned}
d \lambda & =\text { the wavelength displacement } \\
a & =\text { the slope of the sensitivity curve nor- }
\end{aligned}
$$

malized at the center of a triangle, $w=$ the width at the half-height of the geometrical passband.

The wavelength shift is greater for very wide spectral bandwidths and almost negligible for very narrow spectral bandwidths. The effect of instrument sensitivity function is not cancelled by operating the instrument in a double-beam mode. The measured location of emission lines such as those described in section 2.3.1 is not influenced by the instrument sensitivity function because the emission lines are relatively narrow with respect to the spectral bandwidth.

The data for the reflectance minima listed in table 3 and 1 have been adjusted for the influence of the instrument sensitivity function. The amount of adjustment varied from zero where the sensitivity slope was essentially flat to as much as $0.26 \mathrm{~nm}$ where the slope was steep and the spectral bandwidth was $10 \mathrm{~nm}$. For all but 10 of the values listed in these tables, the wavelength shift due to the influence of the instrument sensitivity function was less than $0.1 \mathrm{~nm}$.

\section{Results \\ 4.1 Reflectance of the Rare-Earth Oxide Mixture}

The general reflectance spectrum of the rareearth oxide mixture is illustrated in figures 1-1 through 1-7 for a nominal spectral bandwidth of 4 $\mathrm{mm}$. The absorption bands are numbered in order to associate the data listed in the tables with the spectral features illustrated in the figures.

\subsection{Numerical Results}

Most of the absorption bands appearing in figures 1-1 through 1-7 were analyzed and the recommended values for the wavelengths of minimum reflectance are listed in table 3 for the indicated spectral bandwidths. Preferred bands are identified by asterisks after the band numbers in the table.

\section{Other Measurements}

A check of the reflectance of the $\mathrm{Er}_{2} \mathrm{O}_{3}$ absorption bands at approximately $1012 \mathrm{~nm}$ (Band No. 7) and $1535 \mathrm{~nm}$ (Band No. 23), and $\mathrm{Dy}_{2} \mathrm{O}_{3}$ band at approximately $1260 \mathrm{~nm}$ (Band No. 14) was made on the NBS Reference spectrophotometer for diffuse reflectance [6]. This spectrophotometer uses a 1-meter monochromator equipped with a prism predisperser. The spectral bandwidth was set at 5 


\section{Journal of Research of the National Bureau of Standards}

$\mathrm{nm}$ or $10 \mathrm{~nm}$. The reflectometer is a $30 \mathrm{~cm}$ diameter integrating sphere with a lead-sulfide detector. Measurements are recorded with the wavelength drive set at fixed wavelengths. At each wavelength setting the signal is processed by a current-to-frequency converter and integrated over a 4 second time interval. The reflectance of the sample is measured relative to the sphere wall which is coated with a spectrally neutral white diffuser [5].

The wavelength correction for the reference spectrophotometer was determined by measuring the emission lines of a $\mathrm{Hg}$ lamp at $1013.97 \mathrm{~nm}$ and $1529.58 \mathrm{~nm}$. These measurements indicate that the reference instrument wavelength scale was reading too high by $+0.82 \mathrm{~nm}$ at $1014 \mathrm{~nm}$ and $+0.35 \mathrm{~nm}$ at $1530 \mathrm{~nm}$ for a $5 \mathrm{~nm}$ spectral bandwidth. The reflectance minima of the $\mathrm{Er}_{2} \mathrm{O}_{3}$ bands at approximately $1012 \mathrm{~nm}$ and $1535 \mathrm{~nm}$ are close to the $\mathrm{Hg}$ emission wavelengths. The sample reflectance was measured at $0.2 \mathrm{~nm}$ intervals. From these data, the reflectance minima for band numbers 7,14 , and 23 were determined to be $1012.9 \mathrm{~nm}, 1260.7 \mathrm{~nm}$ and $1535.5 \mathrm{~nm}$ respectively for a spectral bandwidth of $5 \mathrm{~nm}$ after correcting for the wavelength scale error. Band No. 23 was determined to be at 1534.5 $\mathrm{nm}$ for a $10 \mathrm{~nm}$ spectral bandwidth.

A comparison of reflectance minima results for bands 7, 14, and 23 as determined on the VarianCary and Reference spectrophotometers, indicates that a wavelength bias of approximately $1 \mathrm{~nm}$ exists between the two instruments after the wavelength scale has been corrected for all known sources of error (see table 5). Measurements of the reflectance minima made by the Instrumental Research Laboratory [7], of the U.S. Department of Agriculture (USDA) indicate a similar wavelength bias between their spectrophotometers and the VarianCary instrument used in this work. Repeated measurements on the Varian-Cary instrument after 1.5 years indicate that the bias remains constant. Because of the strong evidence for this wavelength bias and confidence in the wavelength accuracy of the NBS Reference spectrophotometer, and the

Table 5. A comparison of the data for reflectance minima numbers 7,14 , and 23 as determined on the Varian-Cary spectrophotometer and the NBS Reference spectrophotometer.

\begin{tabular}{|c|c|c|c|c|}
\hline \multirow[b]{2}{*}{$\begin{array}{c}\text { Band } \\
\text { No. }\end{array}$} & \multirow[b]{2}{*}{$\begin{array}{l}\text { SBW } \\
(\mathrm{nm})\end{array}$} & \multicolumn{2}{|c|}{ Reflectance Minima } & \multirow[b]{2}{*}{$\begin{array}{l}\text { Difference } \\
(2)-(1)\end{array}$} \\
\hline & & $\begin{array}{c}\text { Varian-Cary } \\
\text { Instrument } \\
\text { (1) }\end{array}$ & $\begin{array}{c}\text { Reference } \\
\text { Instrument } \\
\text { (2) }\end{array}$ & \\
\hline 7 & 5 & 1011.8 & 1012.9 & -1.1 \\
\hline 14 & 5 & 1259.8 & 1260.7 & -0.9 \\
\hline 23 & 5 & 1534.4 & 1535.5 & -1.1 \\
\hline 23 & 10 & 1533.6 & 1534.5 & -0.9 \\
\hline
\end{tabular}

supporting evidence from the USDA, the data in table 3 has been adjusted to correct for the VarianCary near infrared wavelength scale bias. The over-all uncertainty of $\pm 1 \mathrm{~nm}$ given in section 2.3.4 remains the same for these adjusted reflectance minima.

\section{Conclusion}

In addition to those uncertainties discussed above there are also other factors that might introduce uncertainties affecting the results of this study. Although these have not been quantitatively investigated, they include: 1) purity of the rareearth oxides. 2) variation in the ratios of the three rare-earths that are mixed to form the specimen, and 3) variation in the density of the pressed pow. der. All three of these factors can be controlled to a high degree of precision in the preparation of the three-component rare-earth mixture used in this study. The purity of the individual constituents is sufficiently high $(99.99 \%)$ so that it is not likely that slight variations in this parameter will affect the location of the wavelengths of minimum reflectance. The ratios of the three rare-earth components was established by careful weighing. For a weighing of $2 \mathrm{~g}$, an uncertainty of $\pm 0.01 \mathrm{~g}$ is too small to have much effect on the location of the wavelengths of minimum reflectance. Mixing of the three components must be thorough, however, to avoid inhomogeneities.

Figures 1-1 through 1-7 should only be used as a key to the appearance of the reflectance spectra. Refer to table 3 for the numerical values. The reflectance data shown in the figures should not be used for purposes of a reflectance standard. The absolute reflectance of pressed Halon [5] has been established for this type of calibration.

A wavelength standard based on the diffuse reflectance of a mixture of three rare-earth oxides has been analyzed and calibrated for the near infrared spectral range 700 to $2000 \mathrm{~nm}$. The reflectance minima obtained from a mixture of $\mathrm{Dy}_{2} \mathrm{O}_{3}, \mathrm{Er}_{2} \mathrm{O}_{3}$, and $\mathrm{Ho}_{2} \mathrm{O}_{3}$ have been determined for nominal spectral bandwidths of $2,3,4,5$, and $10 \mathrm{~nm}$. The principal sources of error influencing the accuracy of the assigned wavelengths of the reflectance minima are the calibration of the spectrophotometer wavelength scale and the imprecision in the techniques used to record and estimate these minima.

This proposed wavelength standard should provide a useful means for checking the accuracy of the near infrared wavelength scale of spectrophotometers equipped with suitable accessories 


\section{Journal of Research of the National Bureau of Standards}

for measuring diffuse reflectance if the required wavelength accuracy does not have to be better than $\pm 1 \mathrm{~nm}$.

An uncertainty of $\pm 1 \mathrm{~nm}$ for this near infrared wavelength standard is less accurate than current wavelength standards for the ultraviolet and visible spectral ranges. A wavelength standard based on a solution of $\mathrm{Ho}_{2} \mathrm{O}_{3}$ in perchloric acid [8] provides 14 transmittance minima for wavelength scale calibration in the ultraviolet and visible spectrum. The overall uncertainty for this wavelength standard is $\pm 0.1 \mathrm{~nm}$ for the location of the transmittance minima.

\section{References}

[1] Certain commercial equipment or products are metioned in this paper in order to adequately document the work. In no case does this imply that the equipment or product is being endorsed by the National Bureau of Standards or that it is necessarily the best equipment or product for the application.

[2] The rare-earth oxides were obtained from Research Chemicals, a division of Nucor Corp., Phoenix, Arizona.

[3] CRC Handbook of Chemistry and Physics, 63rd Edition, CRC Press Inc., (1982-1983).

[4] Acquista, N., and E. K. Plyler, Calibrating Wavelengths in the Region from 0.6 to 2.6 Microns, J. Res. Natl. Bur. Stand., Vol. 49, 13-16 (July 1952).

[5] Weidner, V. R., and J. J. Hsia, Reflection Properties of Pressed Polytetrafluoroethylene Powder, J. Opt. Soc. Am., Vol. 71, 856-861, (July 1981).

[6] Venable, W. H. Jr., J. J. Hsia, and V.R. Weidner, Development of an NBS Reference Spectrophotometer for Diffuse Transmittance and Reflectance, Natl. Bur. Stand., Tech. Note 594-11, October 1976.

[7] Memorandum from: Dr. Karl H. Norris and William R. Hruschka, Instrumentation Research Laboratory, USDA, BARC-W, Beltsville, MD 20912.

[8] Weidner, V. R.; R. Mavrodineanu, K. D. Mielenz, R. A. Velapoldi, K. L. Eckerle, and B. Adams, Spectral Transmittance Characteristics of Holmium Oxide in Perchloric Acid Solution, J. Res. Natl. Bur. Stand., 90-2 (1985). 